Esta obra forma parte del acervo de la Biblioteca Jurídica Virtual del Instituto de Investigaciones Jurídicas de la UNAM

www.juridicas.unam. $m x$

\title{
Entrevista a Diego Fernández de Ceballos
}

Jorge Carpizo: un hombre culto, maestro de muchas generaciones, de inexcusable congruencia y demócrata a carta cabal

1. ¿Cuál fue el contexto político en el que Jorge Carpizo asumió la Secretaría de Gobernación en 1994?

En enero de 1994 ya había iniciado mi campaña como candidato a la presidencia de México cuando se dio el alzamiento armado del llamado EZLN. Cuando el doctor Carpizo fue designado secretario de Gobernación entendí que el gobierno de Carlos Salinas había optado por la vía del diálogo con todas las fuerzas políticas.

2. ¿En qué medida su tesis a favor del proceso de paz y de la negociación con el movimiento zapatista produjeron el cese unilateral del fuego por parte del Gobierno mexicano, y el inicio de la vía política para resolver el conflicto?

La decisión del cese "unilateral del fuego" fue una medida simbólica, ya que el EZLN no tenía capacidad de "fuego". Sin embargo, supongo que la opinión del doctor Carpizo jugó a favor de lo que vendría más tarde: la reforma electoral y la búsqueda de un acuerdo para que los alzados en armas reconsideraran su decisión. 
3. ¿Cuáles fueron las principales aportaciones de Carpizo como responsable de la política interna del País?

Fueron muchas, pero yo estaba en campaña y tenía poco tiempo para seguir a detalle las negociaciones entres los partidos y el gobierno. El jefe nacional del PAN, Carlos Castillo Peraza, fue quien se encargó del asunto; con periodicidad, Carlos me comentaba los avances, en los que siempre contó con mi apoyo.

\section{4. ¿Cuál fue su papel en la convocatoria a la suscripción del Acuerdo Nacional por la Paz, la Justicia y la Democracia en 1994?}

Ese "Acuerdo" fue negociado por Manuel Camacho, a nombre del presidente Carlos Salinas, antes de que Jorge Carpizo fuera designado secretario de Gobernación.

\section{5. ¿En qué momento se decidió impulsar una nueva reforma electoral?}

Esa decisión la tomó el doctor Carpizo en consulta con los presidentes de los tres partidos políticos de mayor peso electoral. Yo no participe en esa consulta, solamente di mi respaldo pleno al jefe nacional del PAN, Carlos Castillo Peraza.

\section{6. ¿Cuál fue el papel de Carpizo en la concretización de la misma?}

No formé parte de la mesa del diálogo en las llamadas "conversaciones de Barcelona, pero el papel del doctor Carpizo fue reconocido por todos los participantes y gracias a él se alcanzaron los acuerdos.

\section{7. ¿Cuáles fueron las principales demandas del PAN, PRI y PRD en la mesa de la negociación de Barcelona?}

Como dije antes, no formé parte de la mesa de negociaciones. Hay varios libros que dan cuenta de las demandas de cada partido, y de lo que se logró, bajo la conducción del doctor Carpizo. 
8. Diga tres momentos destacables del proceso de negociación de la reforma electoral.

Creo que los más destacable de aquella reforma fue la ciudadanización del IFE; los instrumentos para conocer el resultado la misma noche de la jornada electoral y la auditoría al padrón electoral. Lo que faltó fue corregir la enorme inequidad en el acceso a televisión y radio y la gran disparidad de recursos que los partidos tenían por financiamiento público para campaña.

9. ¿Qué importancia le dio Carpizo al consenso para el impulso de los acuerdos políticos?

El compromiso del consenso fue propuesta del doctor Carpizo y fue respetada en todo momento.

10. A su juicio, ¿cuál fue la relevancia de la reforma electoral de 1994?

Mucha.

11. ¿Cuáles fueron los principales retos a los que se enfrentó el proceso electoral de 1994?

Evitó que la percepción de un fraude electoral, como en 1988, se repitiera. Sin embargo, como reconoció Ernesto Zedillo, ya siendo presidente, la elección de 1994 pudo haber sido aparentemente legal, pero no fue equitativa. A mí no me ganó Zedillo, me ganaron Televisa y gobierno del Presidente Salinas.

\section{2. ¿Con qué autoridad condujo Carpizo ese proceso electoral?}

Con la que tuvo y todos le reconocimos. 
13. La primera elección presidencial organizada por el IFE tuvo a Jorge Carpizo como presidente del Consejo General. ¿Cuál fue el sello que imprimió Carpizo a esa elección?

El doctor Carpizo dio a la elección de 1994 un sello personal de imparcialidad, hasta donde podía, siendo secretario de Gobernación en un gobierno del PRI. En lo personal, siempre recordaré su trato respetuoso y su talante democrático. A partir de ese año nos hicimos amigos.

\section{Más allá del ámbito electoral, Carpizo fue un reformador constante del andamiaje institucional de nuestro país, y un incansable constructor de instituciones. ¿Cuáles son, a su juicio, sus principales aportaciones?}

Jorge Carpizo fue un mexicano excepcional; como universitario, como defensor de los derechos humanos, como político; como jurista en cada uno de los cargos que ocupó, dejó una huella indeleble. Muy positiva para México. Fue un hombre de bien que sirvió a México y a la UNAM de manera especial.

15. ¿Cómo calificar su contribución a la transición democrática de México?

Relevante, muy relevante, como pocos han dado.

16. ¿Puede citar algunos ejemplos que den cuenta de su compromiso con el avance democrático de México?

Son muchos, en todos los ámbitos en que participó. Siempre fue un hombre comprometido, antes que nada, con la verdad.

17. Al margen de la persona pública, ¿cómo recuerda a Carpizo en las otras fases de su vida?

Como un gran amigo y estupendo anfitrión, siempre apoyado por Mari, a la que envío mi más afectuoso saludo. Extrañaré su plática, su aguda capacidad para analizar, su respeto para las opiniones de otros y su pasión para defender sus convicciones. 
18. ¿Cuál es el legado que deja Carpizo como político? El de un hombre culto, maestro de muchas generaciones, de inexcusable congruencia y demócrata a carta cabal.

19. ¿Cuál es el legado como jurista, como universitario y como persona?

Como jurista, una obra publicada de enorme valía; como universitario, un esfuerzo para hacer de la UNAM una casa de excelencia. Jorge Carpizo encontró en su alma mater, la UNAM, el motivo profundo de su paso por la vida, a ella dedicó buena parte de su fructífera vida. En lo personal... en mi memoria siempre estará presente el recuerdo de ese gran amigo que fue Jorge Carpizo; su amistad me distinguió y aunque muchas veces no estuvimos de acuerdo, la sinceridad de sus opiniones, la verdad de sus convicciones, son valores que, para mí, lo colocan en un lugar especialísimo en la historia de México.

Termino: aunque Jorge Carpizo era un agnóstico, espero que Dios lo tenga a su lado. Haría bien en designarlo asesor jurídico para los asuntos de los mexicanos.

Por Jorge Carpizo, amigo inolvidable. 